\title{
Efficacy, Safety, and Exposure of Apixaban in Patients with High Body Weight or Obesity and Venous Thromboembolism: Insights from AMPLIFY
}

\author{
Alexander T. Cohen (D) · Sharon Pan · Wonkyung Byon • \\ Bushra S. Ilyas · Thomas Taylor · Theodore C. Lee
}

Received: December 8, 2020 / Accepted: March 18, 2021 / Published online: April 22, 2021

(C) The Author(s) 2021

\section{ABSTRACT}

Introduction: As a result of limited clinical data, guidelines do not recommend the use of non-vitamin $\mathrm{K}$ antagonist oral anticoagulants in patients who weigh $>120 \mathrm{~kg}$ or have a body mass index $(\mathrm{BMI})>40 \mathrm{~kg} / \mathrm{m}^{2}$.

Methods: This post hoc analysis of the AMPLIFY trial evaluated the efficacy (venous thromboembolism [VTE]/VTE-related death), safety (major and composite of major and clinically relevant non-major [CRNM] bleeding), and exposure of apixaban compared with enoxaparin followed by warfarin for the treatment of VTE by body weight $(\leq 60,>60$ to $<100, \geq 100$ to $<120, \geq 120 \mathrm{~kg})$ and $\mathrm{BMI}$ $(\leq 25,>25$ to $30,>30$ to $35,>35$ to 40 , $\left.>40 \mathrm{~kg} / \mathrm{m}^{2}\right)$.

Results: Among the AMPLIFY safety population, 5384 and 5359 patients had recorded body weight (range 28.9 to $222.0 \mathrm{~kg}$; $\geq 120 \mathrm{~kg}$, $n=290$ ) and BMI (range $12.5-71.8 \mathrm{~kg} / \mathrm{m}^{2}$;

Supplementary Information The online version contains supplementary material available at https:// doi.org/10.1007/s12325-021-01716-8.

A. T. Cohen $(\bowtie) \cdot$ T. Taylor

Guy's and St Thomas' Hospitals, Westminster Bridge

Road, London, UK

e-mail: alexander.cohen@kcl.ac.uk

S. Pan - W. Byon - B. S. Ilyas - T. C. Lee

Pfizer, New York, USA $\left.>40 \mathrm{~kg} / \mathrm{m}^{2}, n=263\right)$, respectively. The rates of recurrent VTE/VTE-related death for apixaban versus enoxaparin/warfarin were similar across body weight subgroups: relative risks (RR; 95\% confidence intervals $[\mathrm{CI}])$ were $0.63(0.23,1.72)$, $0.99(0.65,1.50), 0.77(0.34,1.72)$, and 0.20 $(0.02,1.72)$ for the $\leq 60,>60$ to $<100, \geq 100$ to $<120$, and $\geq 120 \mathrm{~kg}$ groups, respectively $\left(P_{\text {interaction }}=0.44\right)$. The rates of major bleeding were lower with apixaban versus enoxaparin/ warfarin; RRs $(95 \% \mathrm{CI})$ were $0.15(0.02,1.15)$, $0.41(0.21,0.77)$, not estimable, and 0.34 (0.04, $3.22)$, respectively $\left(P_{\text {interaction }}=\right.$ not estimable $)$. The rates of major/CRNM bleeding were significantly lower for apixaban versus enoxaparin/ warfarin; RRs $(95 \% \mathrm{CI})$ were $0.46(0.24,0.89)$, $0.49(0.38,0.63), 0.30(0.16,0.58)$, and 0.28 $(0.12,0.66)$, respectively $\left(P_{\text {interaction }}=0.36\right)$. Similar trends were seen in the BMI subgroups. There was a modest, not clinically meaningful, decrease $(<30 \%)$ in the median predicted exposure with increasing body weight $(n=281)$. Conclusions: The findings of this post hoc analysis support the use of apixaban in patients with body weight $\geq 120 \mathrm{~kg}$ or BMI $>40 \mathrm{~kg} / \mathrm{m}^{2}$. Trial Registration Number: NCT00643201 


\section{Graphic Abstract:}

\begin{tabular}{|c|c|c|c|}
\hline \multicolumn{4}{|c|}{$\begin{array}{l}\text { Comparing apixaban with other blood thinners used to treat blood clots in patients who are obese } \\
\text { Alexander T. Cohen, Sharon Pan, Wonkyung Byon, Bushra S. Ilyas, Thomas Taylor, Theodore C. Lee }\end{array}$} \\
\hline $\begin{array}{l}\text { The purpose of this plain language summary } \\
\text { is to help make clear the findings from a } \\
\text { recently published research article. The title of } \\
\text { the research article is Efficacy, safety, and } \\
\text { exposure of apixaban in high body weight and } \\
\text { obese patients with venous thromboembolism: } \\
\text { Insights from AMPLIFY. } \\
\text { The results of this study may differ from those } \\
\text { of other studies. Treatment decisions should } \\
\text { be based on all available evidence, not on the } \\
\text { results of a single study. } \\
\text { This graphical plain language summary } \\
\text { represents the opinions of the authors. For a } \\
\text { full list of declarations, including funding and } \\
\text { author disclosure statements, please see the } \\
\text { full text online. @ The authors, CC-BY-NC } 2021 \text {. }\end{array}$ & $\begin{array}{l}\text { blood clot without incr } \\
\text { is important. } \\
\text { The authors of this stu } \\
\text { patients in the AMPLI } \\
\text { (NCT00643201; clinic } \\
\text { NCT00643201) who v } \\
\text { data from all patients } \\
\text { obese) showed that a } \\
\text { apixaban worked as } \\
\text { bleeding than a comb } \\
\text { called enoxaparin and } \\
\text { (Figure). }\end{array}$ & $\begin{array}{l}\text { asing the risk of bleeding } \\
\text { y looked at data from } \\
\text { clinical trial } \\
\text { trials.gov/ct2/show/ } \\
\text { re obese. Previously, } \\
\text { AMPLIFY (obese and not } \\
\text { ood thinner called } \\
\text { Il as and caused less } \\
\text { ation of two blood thinners } \\
\text { varfarin for treating VTE }\end{array}$ & $\begin{array}{l}\text { What were the results of the study? } \\
\text { The authors found that apixaban worked as well } \\
\text { as enoxaparin and warfarin in reducing the risk of } \\
\text { having another VTE or VTE-related death and } \\
\text { lowered the risk of bleeding in patients with VTE } \\
\text { who were obese. } \\
\text { They also found that as a patient's body weight } \\
\text { increased, the amount of apixaban in their } \\
\text { bloodstream decreased. But this did not affect how } \\
\text { well the drug worked. } \\
\text { What do the authors think these results mean? } \\
\text { Overall, these findings support treating VTE with } \\
\text { apixaban in patients who are obese. } \\
\text { More research is needed to confirm these findings. }\end{array}$ \\
\hline
\end{tabular}

Keywords: Apixaban; Body mass index; Body weight; Enoxaparin; Venous thromboembolism; Warfarin

\section{Key Summary Points}

Why carry out this study?

Obesity, which has a rising worldwide prevalence, is associated with an increased risk of venous thromboembolism (VTE) and recurrent VTE. Current guidelines do not recommend the use of non-vitamin $\mathrm{K}$ antagonist oral anticoagulants in patients who weigh $>120 \mathrm{~kg}$ or have a body mass index (BMI) $>40 \mathrm{~kg} / \mathrm{m}^{2}$ because of limited clinical data in this population.

This post hoc analysis of the AMPLIFY trial extends previous subgroup analyses to explore the efficacy, safety, and exposure of apixaban for the treatment of VTE in patients with a body weight $\geq 120 \mathrm{~kg}$ or BMI $>40 \mathrm{~kg} / \mathrm{m}^{2}$.

\section{What was learned from the study?}

The efficacy and safety of apixaban in patients with body weight $\geq 120 \mathrm{~kg}$ or BMI $>40 \mathrm{~kg} / \mathrm{m}^{2}$ were consistent with the main results of the AMPLIFY trial.

Across the different body weight and BMI categories, including body weight $\geq 120 \mathrm{~kg}$ and $\mathrm{BMI}>40 \mathrm{~kg} / \mathrm{m}^{2}$, apixaban had similar rates of recurrent VTE or VTE-related death and lower rates of bleeding compared with enoxaparin/warfarin.

There were no clinically meaningful differences in apixaban exposure between patients with body weight $\geq 120 \mathrm{~kg}$ and those in lower body weight groups.

\section{DIGITAL FEATURES}

This article is published with digital features, including a summary slide and graphical plain language summary, to facilitate understanding 
of the article. To view digital features for this article go to https://doi.org/10.6084/m9. figshare.13705642.

\section{INTRODUCTION}

Obesity affects over 650 million adults worldwide; between 1975 and 2016, the worldwide prevalence of obesity nearly tripled and continues to increase [1]. Obesity is a risk factor for thrombotic disorders, including venous thromboembolism (VTE), due to disruption of the balance between prothrombotic and antithrombotic adipokines, which leads to chronic inflammation, impaired fibrinolysis, and enhanced platelet activation inducing the coagulation cascade $[2,3]$. Studies have reported up to a 6.2 -fold increase in the risk of VTE due to obesity [4-6].

The International Society on Thrombosis and Haemostasis guidelines for the treatment of VTE do not recommend the use of non-vitamin $\mathrm{K}$ antagonist oral anticoagulants (NOACs) in patients who weigh $>120 \mathrm{~kg}$ or have a body mass index $(\mathrm{BMI})>40 \mathrm{~kg} / \mathrm{m}^{2}$ because of limited clinical data in this population [7]. In addition, there is some concern regarding underdosing with NOACs in patients in this body weight or BMI category with VTE because of decreased drug exposures, reduced peak concentrations, and shorter half-lives with increasing weight [7].

Apixaban, a factor Xa (FXa) inhibitor, is approved for the treatment and secondary prevention of VTE, the prophylaxis of VTE after hip or knee surgery, and the prevention of stroke in patients with non-valvular atrial fibrillation [8]. It is administered in fixed doses with no dose adjustment for body weight alone [8]. A population pharmacokinetic (PK) analysis showed that apixaban PK characteristics in patients with VTE were generally consistent with observations in healthy subjects [9]. Additionally, no statistically significant relationship was found between apixaban exposure and clinical endpoints in an exposure-response analysis [9]. A PK study in healthy subjects, using a single dose of apixaban $(10 \mathrm{mg})$, showed that apixaban exposure (AUC) was approximately 23\% lower in the high body weight ( $\geq 120 \mathrm{~kg}$ ) group and approximately $20 \%$ higher in the low body weight $(\leq 50 \mathrm{~kg})$ group compared with the reference group (65-85 kg) [10]. These modest changes in exposure were not considered to be clinically meaningful.

The AMPLIFY trial (NCT00643201), an active-controlled, parallel-group, double-blind, triple-dummy, randomized study, showed that a 6-month treatment course of oral apixaban monotherapy was non-inferior to enoxaparin followed by warfarin in reducing the rate of recurrent VTE or VTE-related death and was associated with less major bleeding [11]. Consistent results were demonstrated in subgroup analyses of VTE or VTE-related death and major bleeding by body weight $(\leq 60,>60$ to $<100$, and $\geq 100 \mathrm{~kg})$ and BMI $(\leq 25,>25$ to $30,>30$ to 35 , and $>35 \mathrm{~kg} / \mathrm{m}^{2}$ ) [11]. However, the efficacy and safety of apixaban in patients with body weight $\geq 120 \mathrm{~kg}$ and $\mathrm{BMI}>40 \mathrm{~kg} / \mathrm{m}^{2}$ remain unknown. The objective of this post hoc analysis of the AMPLIFY trial was to extend the previous subgroup analyses to explore the efficacy, safety, and exposure of apixaban for the treatment of VTE in patients with a body weight $\geq 120 \mathrm{~kg}$ or $\mathrm{BMI}>40 \mathrm{~kg} / \mathrm{m}^{2}$.

\section{METHODS}

\section{Study Design and Population}

The study design, methods, and primary results of the AMPLIFY trial have been published previously [11]. Briefly, patients were eligible for inclusion in the study if they were aged 18 years or older with an objectively confirmed, symptomatic proximal deep vein thrombosis (DVT) involving the popliteal, femoral, or iliac veins, or acute symptomatic pulmonary embolism (PE) with or without DVT. Exclusion criteria were active bleeding, a high risk of bleeding, or other contraindications to treatment with enoxaparin and warfarin. Patients with cancer whose VTE was to be treated for 6 months or more with low molecular weight heparin were excluded. Patients were also excluded if their DVT or PE was provoked in the absence of a persistent risk factor for recurrence; if less than 
6 months of anticoagulant treatment was planned; or if they had another indication for longterm anticoagulation therapy, dual antiplatelet therapy, treatment with aspirin at a dosage of more than $165 \mathrm{mg}$ daily, or treatment with potent inhibitors of cytochrome P450 3A4.

The protocol was approved by the institutional review board of each participating study center (full list of institutional review boards that approved the study is included as supplementary material). All patients provided written informed consent. This study was conducted in accordance with the Declaration of Helsinki. An independent committee unaware of study group assignments adjudicated all suspected outcomes. No patients were involved in the design of the study or the dissemination of the results.

Randomization was stratified by the qualifying index event (DVT alone or PE with or without DVT). Eligible patients were randomized 1:1 to apixaban (10 mg twice daily) for the first 7 days followed by $5 \mathrm{mg}$ twice daily for 6 months, or to subcutaneous enoxaparin $(1 \mathrm{mg} / \mathrm{kg}$ of body weight every $12 \mathrm{~h}$ ) for at least 5 days and warfarin initiated concomitantly and continued for 6 months. The warfarin dosage was adjusted to an international normalized ratio (INR) of 2.0-3.0. Enoxaparin was discontinued when a blinded INR of 2.0 or more was achieved. To measure apixaban plasma concentrations, blood samples were collected at steady state at $-2 \mathrm{~h}$ (ca. $2 \mathrm{~h}$ prior to dosing), $0 \mathrm{~h}$ (pre-dose), and 2 and $4 \mathrm{~h}$ post-dose [9].

\section{Outcomes}

In this post hoc analysis, patients were analyzed according to body weight $(\leq 60,>60$ to $<100$, $\geq 100$ to $<120$, and $\geq 120 \mathrm{~kg}$ ) and BMI categories ( $\leq 25,>25$ to $30,>30$ to $35,>35$ to 40 , and $\left.>40 \mathrm{~kg} / \mathrm{m}^{2}\right)$.

The primary efficacy outcome was the incidence of the adjudicated composite of recurrent symptomatic VTE or VTE-related death. Recurrent VTE included fatal or nonfatal PE and DVT. Causes of death were classified as related to VTE, cardiovascular disease, bleeding, or other causes. PE was considered the cause of death if there was objective documentation, or if death could not be attributed to another documented cause and PE could not be ruled out.

The primary safety outcome was adjudicated major bleeding and the secondary safety outcome was the composite of major bleeding and clinically relevant non-major (CRNM) bleeding. Major bleeding was defined as overt bleeding associated with a decrease in the hemoglobin level of $\geq 2 \mathrm{~g} / \mathrm{dL}$, requiring the transfusion of $\geq 2$ units of blood, occurring into a critical site (intracranial, intraspinal, intraocular, pericardial, intra-articular, intramuscular with compartment syndrome, or retroperitoneal), or contributing to death. CRNM bleeding was defined as overt bleeding not meeting the criteria for major bleeding but associated with medical intervention, contact with a physician, interruption of the study drug, or discomfort or impairment in carrying out activities of daily life. The criteria for the diagnosis and adjudication of all outcomes have been previously reported [11].

Finally, a population PK analysis was conducted to characterize apixaban exposure in patients treated for VTE as published previously [9].

\section{Statistical Analysis}

All efficacy analyses included data for patients in the intention-to-treat population for whom the outcome status at 6 months was documented. Patients with missing endpoint events were excluded from the efficacy analysis. All safety analyses included data obtained from treated patients during the study treatment period, defined as the time from the administration of the first dose until $48 \mathrm{~h}$ after the last dose was administered.

For each subgroup, the relative risk (RR) and 95\% confidence intervals (CIs) were calculated using the Cochran-Mantel-Haenszel test, stratified by index event strata. The 95\% CIs for single event rates were calculated on the basis of the Wald asymptotic confidence limits. $P$ values for interaction were based on a logistic model using Wald's chi-square test. 
Using the published population PK analysis of apixaban in patients undergoing VTE treatment, steady-state daily (0-24 h) exposure was predicted for each patient using the empirical Bayes' prediction of their oral clearance value from the final population PK model and total daily dosage of apixaban, and was summarized by body weight category [9].

\section{RESULTS}

\section{Patient Population and Baseline Characteristics}

Of the 5395 patients who were randomized and included in the safety population of AMPLIFY, 5384 and 5359 patients had recorded body weight and BMI, respectively. The ranges of body weight and BMI for the trial were $28.9-222.0 \mathrm{~kg}$ and $12.5-71.8 \mathrm{~kg} / \mathrm{m}^{2}$, respectively. Among these patients, 290 had a body weight $\geq 120 \mathrm{~kg}$ and $263 \mathrm{had}$ a BMI $>40 \mathrm{~kg} / \mathrm{m}^{2}$. The baseline demographics and clinical characteristics of patients by body weight group are shown in Table 1 . Patients in the $\geq 120 \mathrm{~kg}$ group were younger than those in lower body weight groups and were less likely to be female than those in the $\leq 60$ and $>60$ to $<100 \mathrm{~kg}$ body weight groups. As expected, mean BMI increased across body weight groups. Creatinine clearance was normal in most patients who weighed $\geq 100$ to $<120$ or $\geq 120 \mathrm{~kg}$. The clinical presentation of VTE did not differ by body weight group; however, patients weighing $\geq 100$ to $<120$ or $\geq 120 \mathrm{~kg}$ were more likely to have had a previous VTE than those in lower weight groups. There was an increase in the percentage of patients with diabetes, hypercholesterolemia, and hypertension with increasing body weight.

The baseline demographic and clinical characteristics of patients by BMI category are shown in Table 2. Similar trends were seen across BMI groups as for body weight groups with some exceptions: age was similar among BMI groups and patients were more likely to be female in higher BMI groups.

\section{Efficacy and Safety Outcomes}

The rates of recurrent VTE or VTE-related death were similar between apixaban-treated and enoxaparin/warfarin-treated patients across body weight groups (Fig. 1a). The RRs (95\% CI) for the $\leq 60,>60$ to $<100$, and $\geq 100$ to $<120 \mathrm{~kg}$ groups were $0.63(0.23,1.72), 0.99$ $(0.65,1.50)$, and $0.77(0.34,1.72)$, respectively. The $\geq 120 \mathrm{~kg}$ group had the lowest RR: 0.20 (95\% CI 0.02, 1.72). No treatment by body weight interaction was observed $\left(P_{\text {interaction }}=\right.$ $0.44)$.

Major bleeding rates were numerically lower with apixaban compared with enoxaparin/warfarin across body weight groups with point estimates of RR of 0.15 to 0.41 (Fig. 1b). The RR (95\% CI) of major bleeding for the $\geq 120 \mathrm{~kg}$ group was $0.34(0.04,3.22)$. No major bleeding episodes were reported in the $\geq 100$ to $<120 \mathrm{~kg}$ group receiving apixaban; thus, the $P_{\text {interaction }}$ for treatment by body weight was not estimable.

The rates of major or CRNM bleeding were significantly lower in apixaban-treated patients compared with enoxaparin/warfarin-treated patients across all body weight groups (Fig. 1c). The RRs $(95 \% \mathrm{CI})$ for the $\leq 60,>60$ to $<100$, $\geq 100$ to $<120$, and $\geq 120 \mathrm{~kg}$ groups were 0.46 (0.24, 0.89), 0.49 (0.38, 0.63), $0.30(0.16,0.58)$, and $0.28(0.12,0.66)$, respectively. No treatment by body weight interaction was observed $\left(P_{\text {interaction }}=0.36\right)$.

The efficacy and safety results by BMI group were similar to those seen across body weight groups (Fig. 2).

\section{Exposure Outcomes}

Apixaban plasma concentrations were measured for 281 patients: $16,199,45$, and 21 patients in the $\leq 60,>60$ to $<100, \geq 100$ to $<120$, and $\geq 120 \mathrm{~kg}$ body weight groups, respectively. There was a modest decrease $(<30 \%)$ in the median predicted exposure with increasing body weight (Fig. 3). The exposure range was similar among body weight categories with overlapping quartiles. 


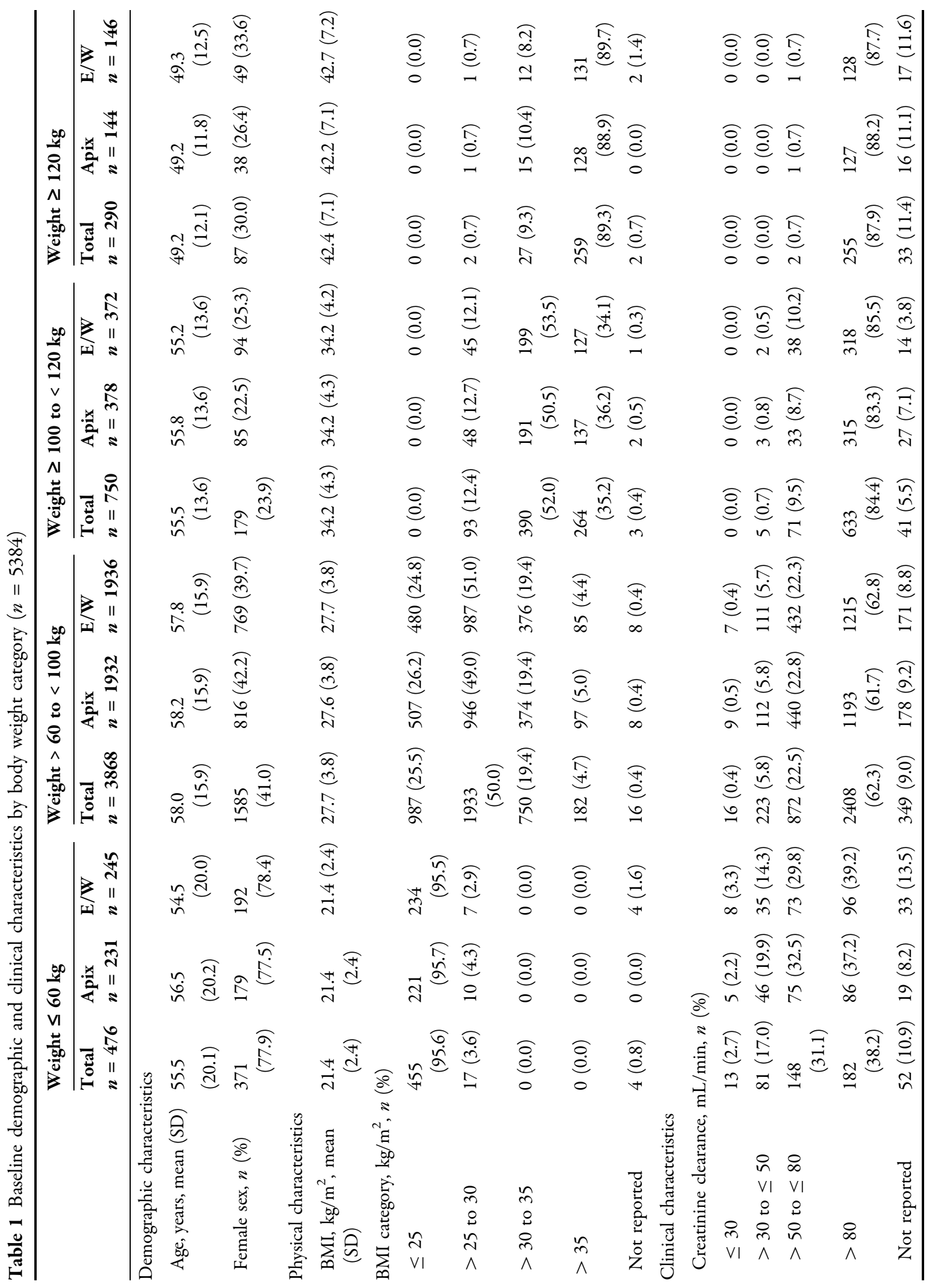




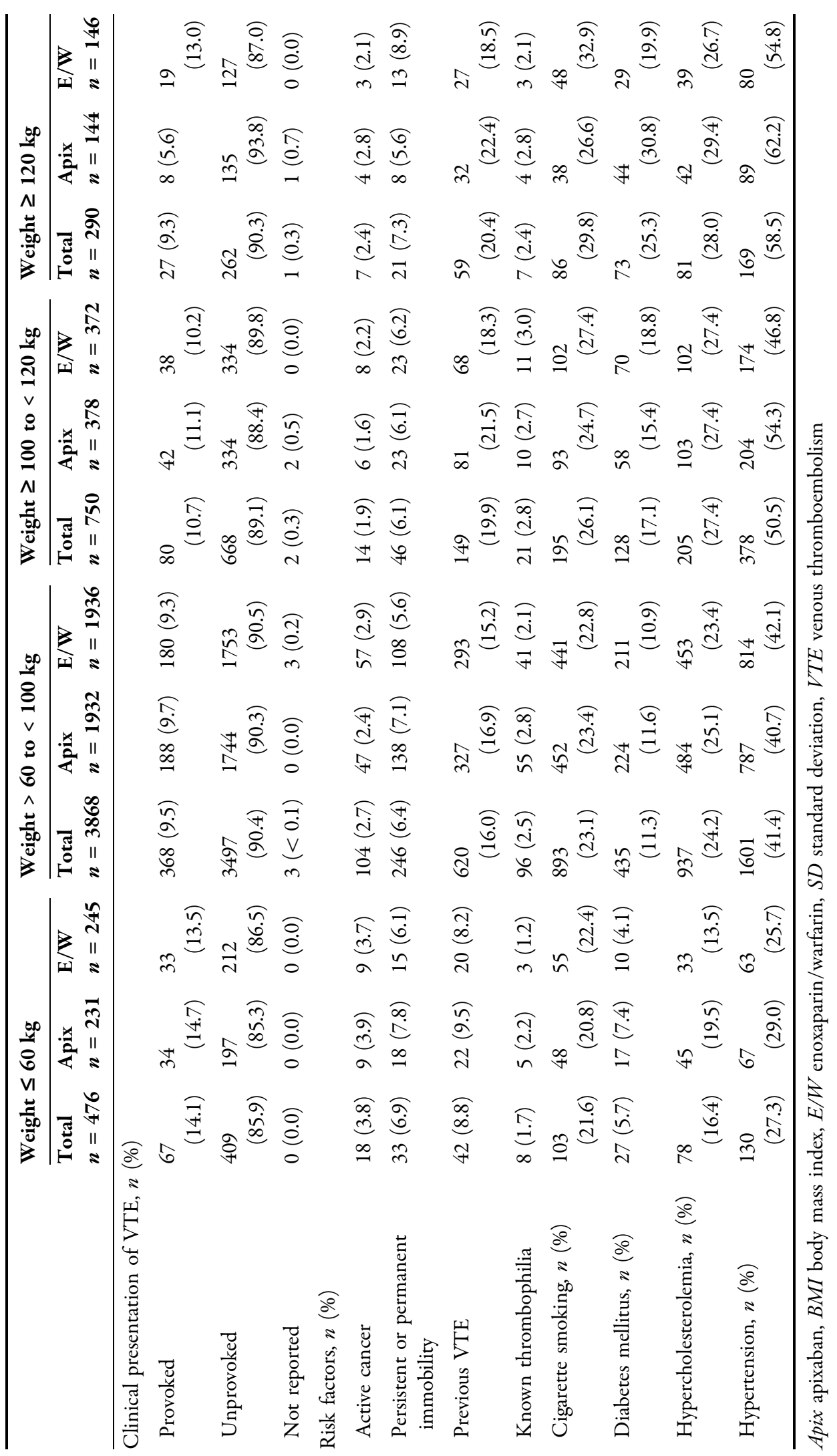




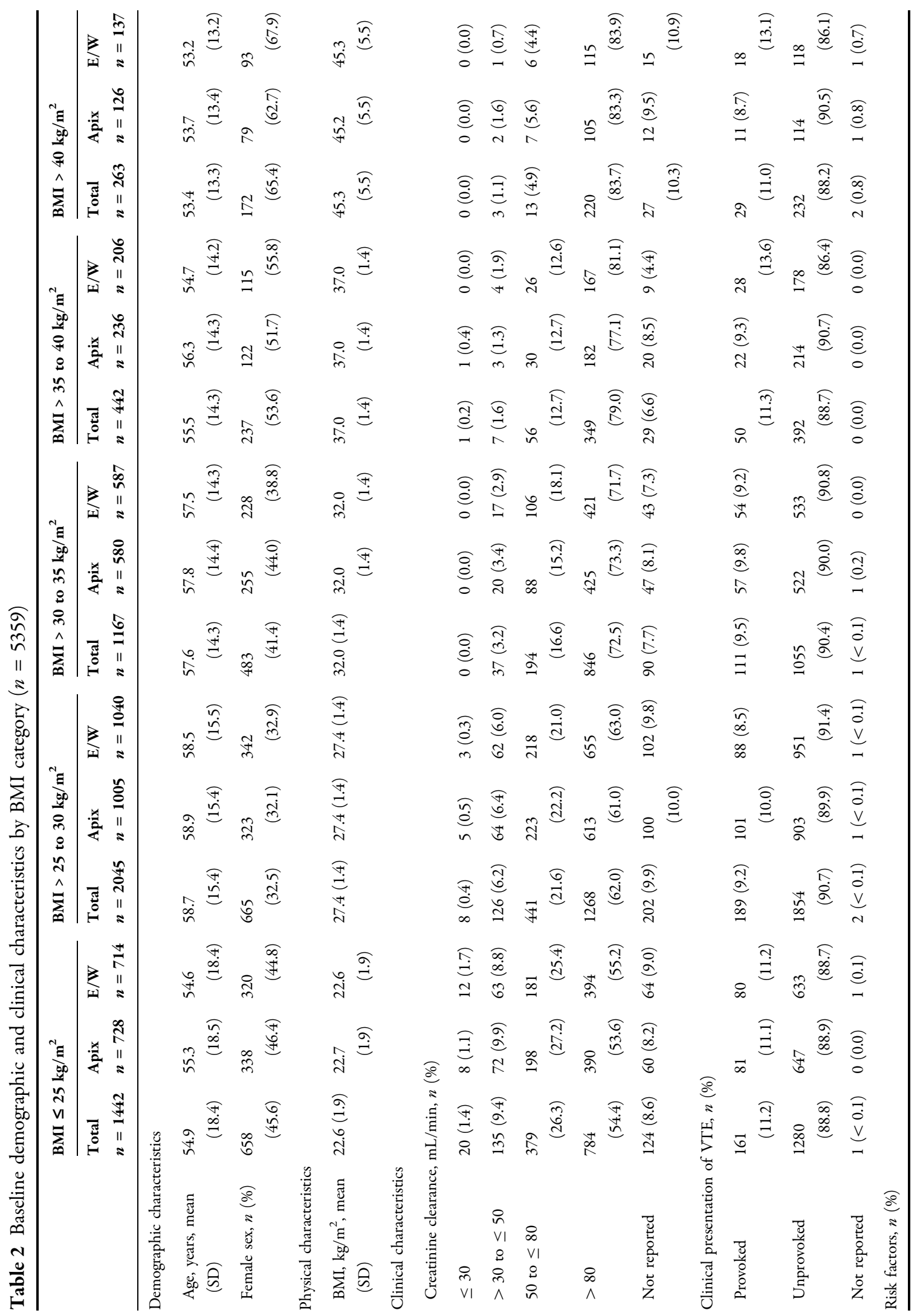




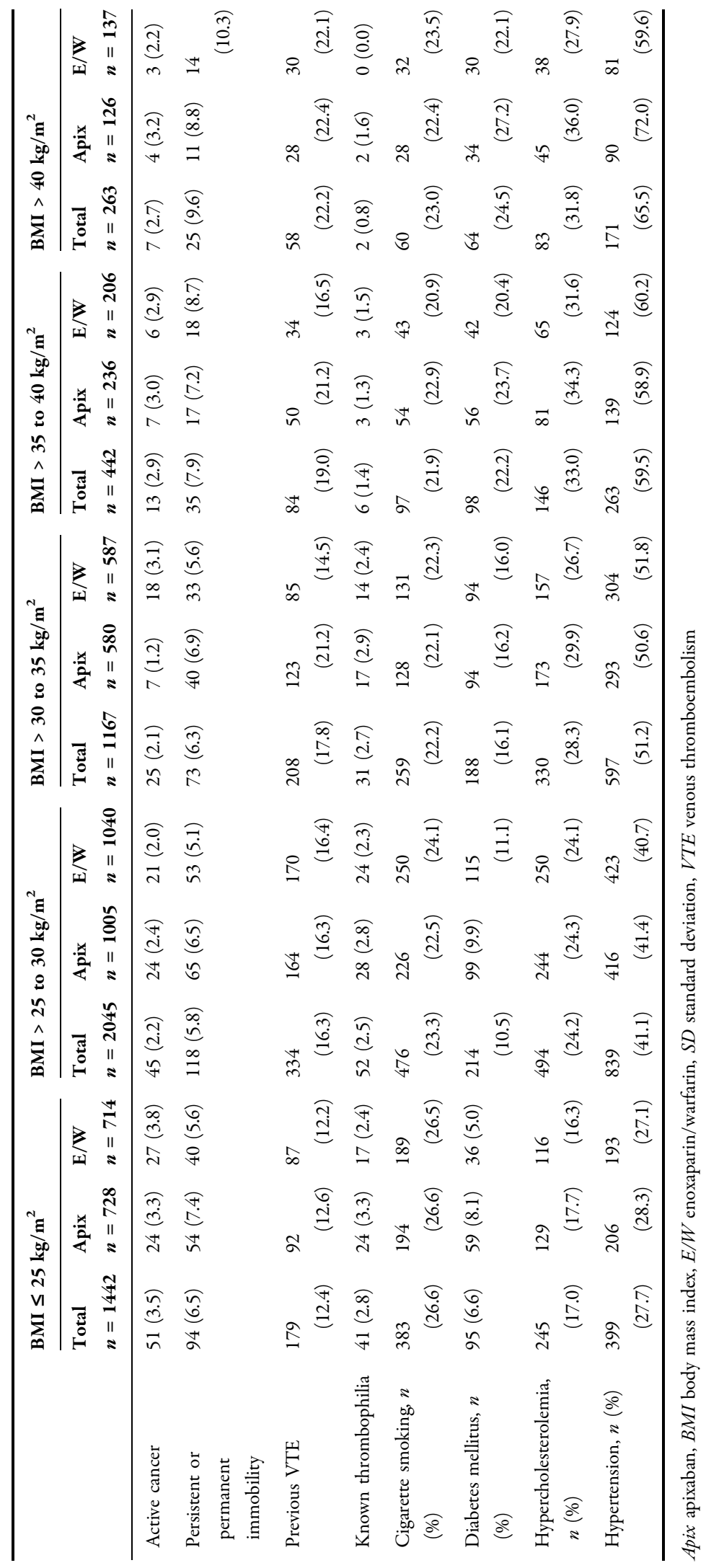




\section{VTE or VTE-related death}

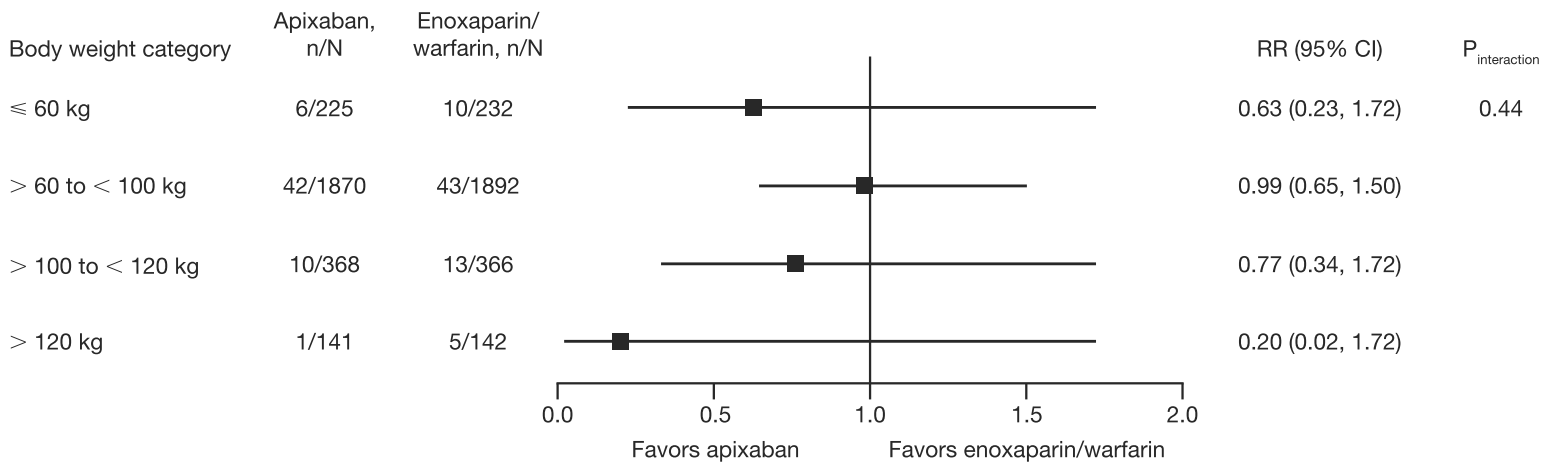

\section{Major bleeding}

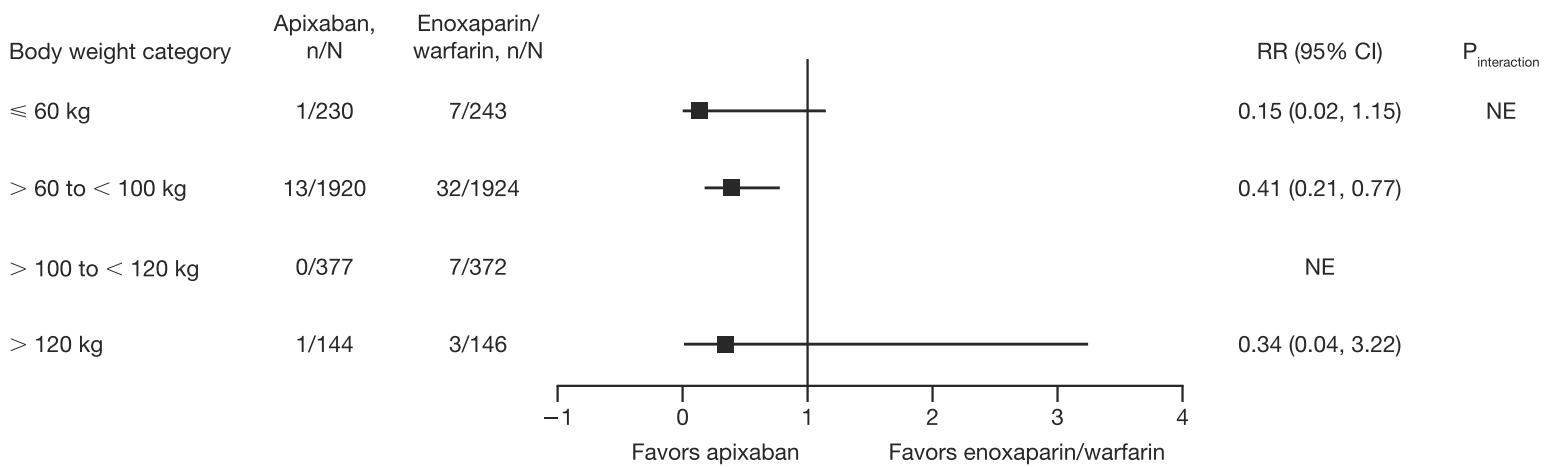

\section{Major or CRNM bleeding}

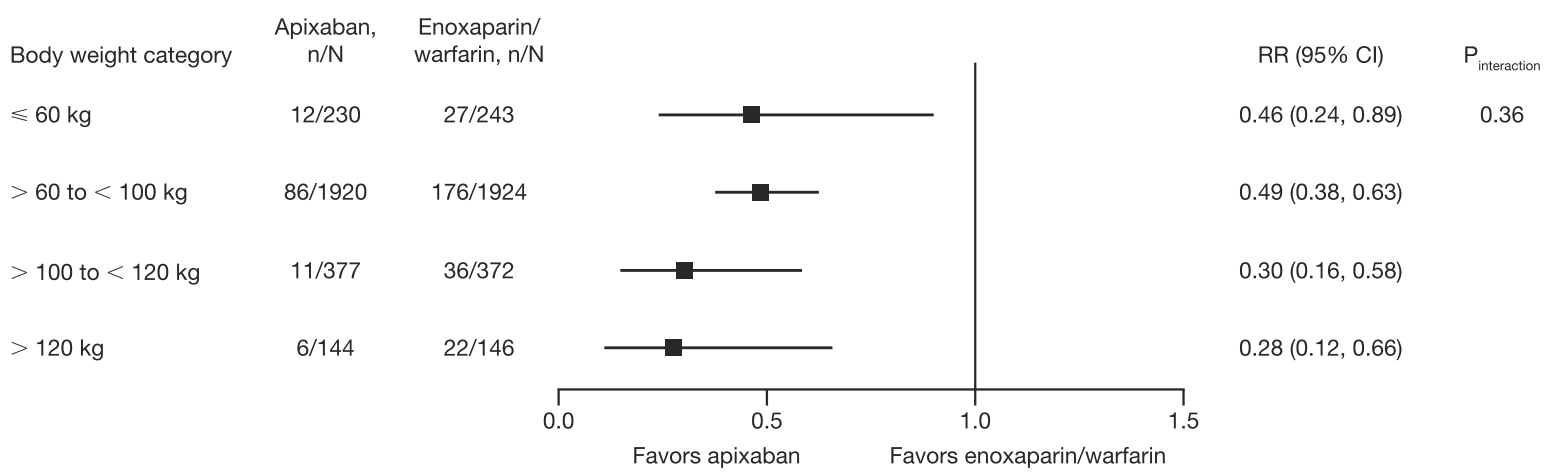

Fig. 1 Recurrent VTE or VTE-related death, major bleeding, and composite of major or CRNM bleeding during the treatment period by body weight category. $C I$ confidence interval, $C R N M$ clinically relevant non-major, $N E$ not estimable, $R R$ relative risk, $V T E$ venous thromboembolism 


\section{DISCUSSION}

The presumed decrease in NOAC exposure in patients with body weight $\geq 120 \mathrm{~kg}$ or $\mathrm{BMI}>40 \mathrm{~kg} / \mathrm{m}^{2}$ has raised concern regarding potential underdosing and associated lack of efficacy in patients with VTE. Therefore, this post hoc analysis focused on patients with body weight $\geq 120 \mathrm{~kg}$ or BMI of $>40 \mathrm{~kg} / \mathrm{m}^{2}$ with VTE who participated in the AMPLIFY trial. Compared with enoxaparin/warfarin, fixed-dose apixaban without any dose adjustments was not associated with a higher risk of recurrent VTE or VTE-related death in patients with VTE, including those with body weight $\geq 120 \mathrm{~kg}$ or BMI $>40 \mathrm{~kg} / \mathrm{m}^{2}$. Consistent with the overall results of the AMPLIFY trial [11], the rates of recurrent VTE or VTE-related death were similar between treatments, with lower rates of bleeding (major and composite of major and CRNM bleeding) occurring with apixaban compared with enoxaparin/warfarin across increasing body weight and BMI groups, including in those with obesity and high body weight.

Apixaban exposures by body weight category were consistent with the overall population PK analysis [9]. Among the subset of AMPLIFY patients in whom apixaban plasma concentrations were measured, there was a modest decrease of $<30 \%$ in apixaban exposure in the $\geq 120 \mathrm{~kg}$ group compared with the $>60$ to $<100 \mathrm{~kg}$ group, which had the most patients. The magnitude of this decrease is consistent with the results of a study of apixaban exposure in healthy subjects with extremes of body weight [10]. This is not considered clinically meaningful because similar magnitudes of changes have been observed in male individuals, or patients with moderate renal impairment, or patients receiving concomitant diltiazem, a moderate inhibitor of CYP3A4, without altering the benefit-risk profile of apixaban or requiring dose adjustment $[10,12-14]$. This is supported by the observed relative risk of recurrent VTE or VTE-related death in apixaban-treated patients in the $\geq 120 \mathrm{~kg}$ and $>40 \mathrm{mg} / \mathrm{kg}^{2}$ groups being no greater than that in lower body weight or BMI groups. Additionally, an observational study in
100 patients with a median BMI of $45 \mathrm{~kg} / \mathrm{m}^{2}$ found that obese or high body weight patients typically achieve therapeutic FXa inhibitor concentrations, with no relationship between FXa inhibitor concentrations at peak or trough and body weight or BMI [15]. Thus, despite the modest decrease in apixaban exposure in the $\geq 120 \mathrm{~kg}$ group, our analysis does not suggest that high body weight or obesity unfavorably affect the efficacy of apixaban for the treatment of VTE.

Evidence for NOAC use in patients with extremes of body weight is sparse, both for the treatment of VTE and the prevention of stroke in patients with non-valvular atrial fibrillation; however, apixaban and rivaroxaban appear to have the most favorable efficacy and safety profiles $[16,17]$. The EINSTEIN DVT/PE studies showed no association between body weight $(\leq 50,>50$ to $<100, \geq 100 \mathrm{~kg})$ or BMI $(<25$, $\geq 25$ to $<30, \geq 30$ to $<35$, and $\geq 35 \mathrm{~kg} / \mathrm{m}^{2}$ ) and risk of recurrent VTE $\left(P_{\text {trend }}=0.87\right.$ and 0.62 , respectively), major bleeding $\left(P_{\text {trend }}=0.24\right.$ and 0.36 , respectively), or clinically relevant bleeding ( $P_{\text {trend }}=0.17$ and 0.63 , respectively) in rivaroxaban-treated patients. Major bleeding events were numerically lower in rivaroxabantreated patients across all body weight and BMI categories [18]. The pre-specified subgroup analysis of the AMPLIFY trial by body weight $(\leq 60,>60$ to $<100$, and $\geq 100 \mathrm{~kg}$ ) showed no significant differences between apixaban and enoxaparin/warfarin for the outcome of recurrent VTE; furthermore, apixaban-treated patients had a lower rate of major bleeding [11]. Similar results were shown for BMI groups $\left(\leq 25,>25\right.$ to $30,>30$ to 35 , and $\left.>35 \mathrm{~kg} / \mathrm{m}^{2}\right)$. The current analysis confirms and extends these results in obese patients with body weight $\geq 120 \mathrm{~kg}$ or BMI $>40 \mathrm{~kg} / \mathrm{m}^{2}$.

Several observational studies have shown that NOACs have a similar effectiveness and similar rates of bleeding compared with warfarin in obese patients treated for VTE; however, most of these studies did not differentiate between individual NOACs. A meta-analysis of five observational studies showed that the use of NOACs in obese patients with body weight $>120 \mathrm{~kg}$ or BMI $>40 \mathrm{~kg} / \mathrm{m}^{2}$ was non-inferior to warfarin with regard to effectiveness (VTE 


\section{VTE or VTE-related death}

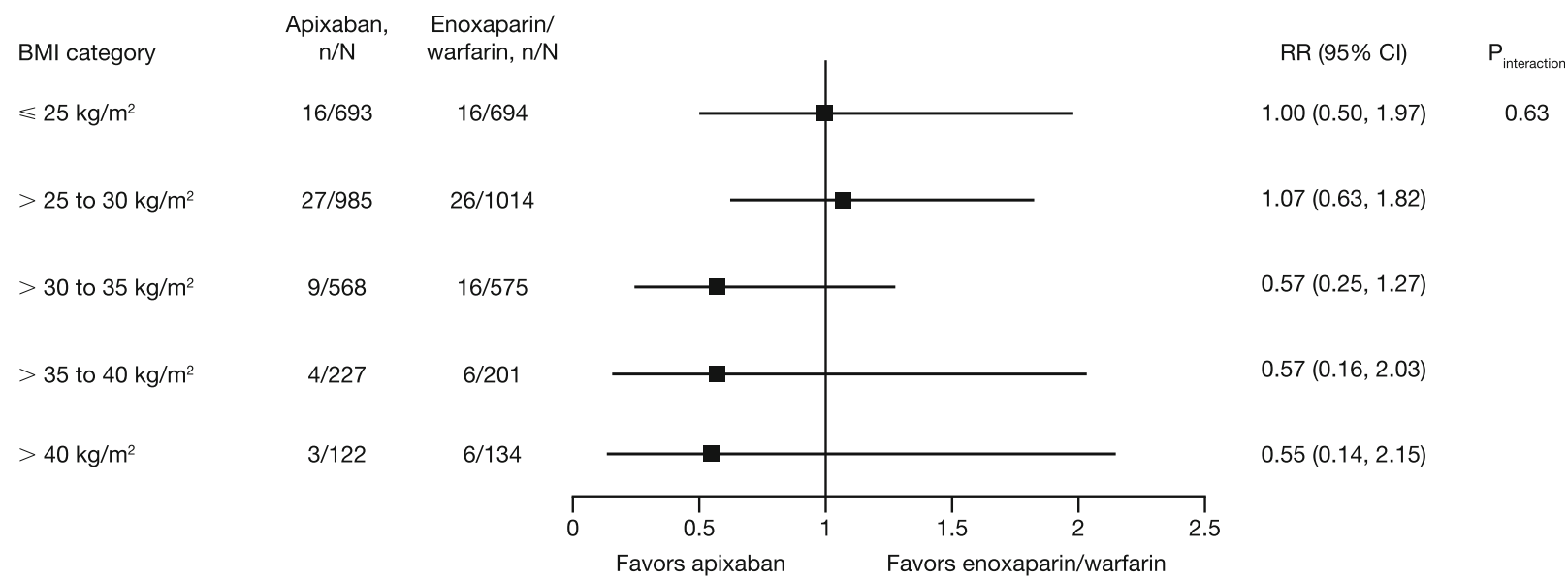

\section{Major bleeding}
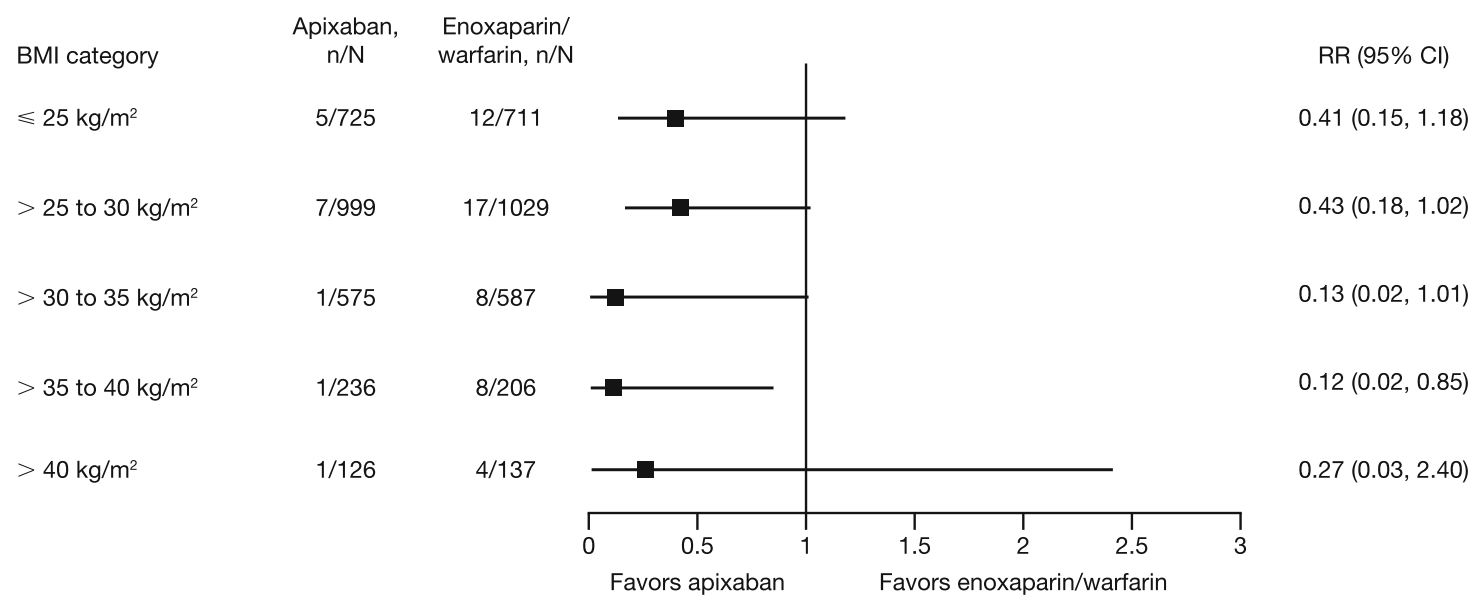

\section{Major or CRNM bleeding}

$\begin{array}{lcc}\text { BMl category } & \begin{array}{c}\text { Apixaban, } \\ \mathrm{n} / \mathrm{N}\end{array} & \begin{array}{c}\text { Enoxaparin/ } \\ \text { warfarin, } \mathrm{n} / \mathrm{N}\end{array} \\ \leqslant 25 \mathrm{~kg} / \mathrm{m}^{2} & 35 / 725 & 60 / 711 \\ >25 \text { to } 30 \mathrm{~kg} / \mathrm{m}^{2} & 33 / 999 & 89 / 1029 \\ >30 \text { to } 35 \mathrm{~kg} / \mathrm{m}^{2} & 29 / 575 & 64 / 587 \\ >35 \text { to } 40 \mathrm{~kg} / \mathrm{m}^{2} & & \\ >40 \mathrm{~kg} / \mathrm{m}^{2} & 12 / 236 & 29 / 206 \\ & & 17 / 137 \\ & 5 / 126 & \\ & & \end{array}$

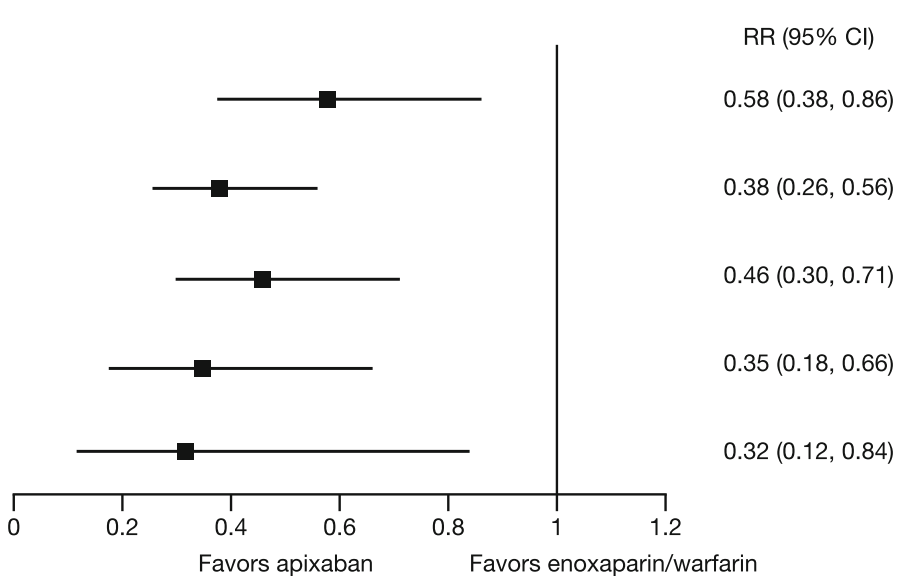


Fig. 2 Recurrent VTE or VTE-related death, major bleeding, and composite of major or CRNM bleeding during the treatment period by BMI category. BMI body mass index, $C I$ confidence interval, $C R N M$ clinically relevant non-major, $R R$ relative risk, $V T E$ venous thromboembolism

recurrence) and safety (major bleeding) [19]. Further observational studies have shown consistent results. A retrospective cohort study in 1840 obese patients $(>100$ and $<300 \mathrm{~kg}$ ) with acute VTE treated at an integrated delivery system of 40 academic, community, and specialty hospitals in the USA found that NOACs and warfarin had similar effectiveness and safety (no significant differences in the rates of VTE recurrence or bleeding, respectively) [20]. Another study in 366 patients with a $\mathrm{BMI} \geq 40 \mathrm{~kg} / \mathrm{m}^{2}$ prescribed an anticoagulant for venous thromboembolism (apixaban, $n=47$; rivaroxaban, $n=152$; warfarin, $n=167$ ) found the incidences of recurrent VTE and major bleeding to be similar between each NOAC and warfarin [21]. An analysis of the Mayo Clinic VTE Registry consisting of 2577 patients with VTE receiving anticoagulant treatment (apixaban, $n=772$; rivaroxaban, $n=502$ ) found similar rates of recurrent VTE and major bleeding between apixaban-treated and rivaroxabantreated patients across body weight groups $(<60,60$ to 120 , and $>120 \mathrm{~kg})$ [22]. Observational data comparing rivaroxaban with warfarin are available from a propensity scorematched analysis using pooled data from two US claims databases. Results showed that morbidly obese patients (based on ICD-9/10 codes) with VTE treated with rivaroxaban had similar risks of recurrent VTE and major bleeding compared with those treated with warfarin [23].

Because our analysis was performed in the setting of a randomized, double-blind, activecontrolled clinical trial, the possibility of treatment selection bias and treatment-related management decisions are minimized. Other strengths of this analysis are the inclusion of patients with extremes of body weight, particularly $\geq 120 \mathrm{~kg}$ and $\mathrm{BMI}>40 \mathrm{~kg} / \mathrm{m}^{2}$; central adjudication of all VTE and bleeding events by an independent committee blinded to treatment assignment; and assessment of apixaban exposure from a representative set of study patients which spanned across all body weight and BMI categories. However, the results of this post hoc analysis are only hypothesis-generating. As body weight and BMI were assessed only at baseline, clinical outcomes may have been impacted by any body weight and BMI changes among patients during the trial. In addition, because patients in a clinical trial tend to have fewer comorbidities and concomitant medications, apixaban exposure may be different in a real-world population, and this could be further pronounced in the obese population. Other limitations of this analysis include the low

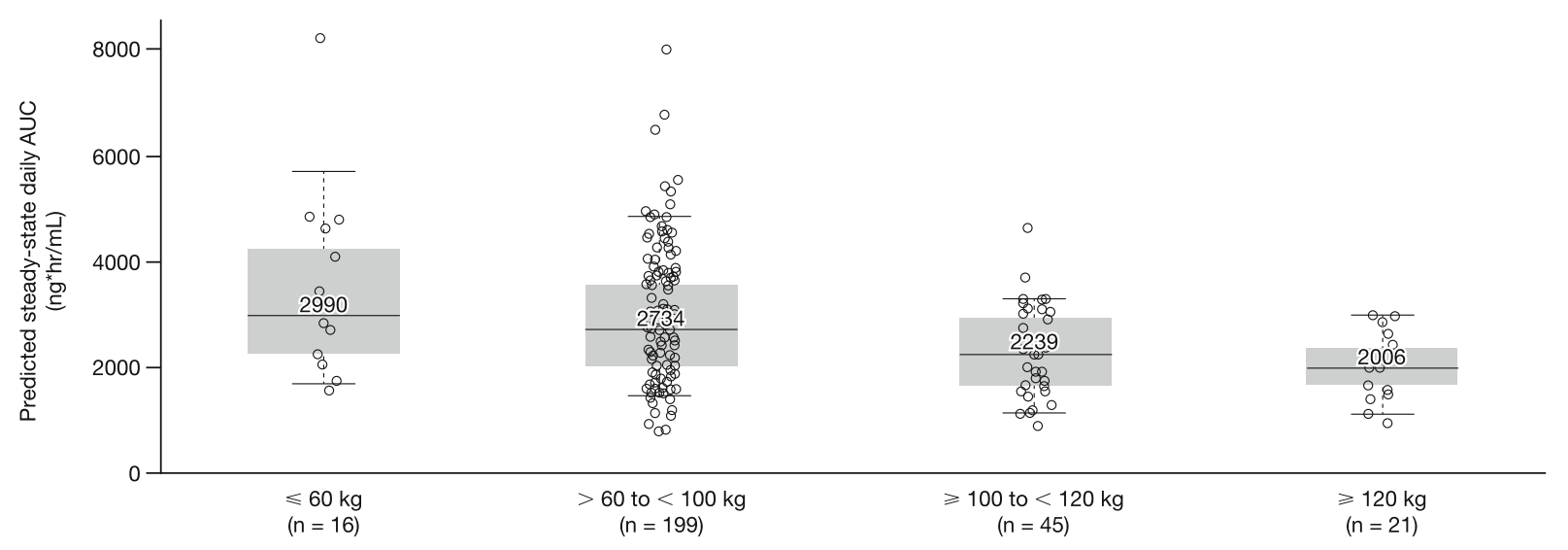

Fig. 3 Predicted steady-state daily AUC by body weight category. Boxes indicate 25th to 75th percentiles, whiskers indicate 5th to 95th percentiles, and black horizontal lines represent the median. Numbers inside boxes are median values. Circles are individual predicted values. $A U C$ area under the plasma concentration-time curve 
numbers of patients in the $\geq 120 \mathrm{~kg}$ body weight and $\mathrm{BMI}>40 \mathrm{~kg} / \mathrm{m}^{2}$ groups, a small number of patients (approximately 5\% of patients in AMPLIFY) in the population PK analysis, and a relatively short follow-up duration.

\section{CONCLUSIONS}

In this post hoc analysis, the efficacy and safety of apixaban in patients with body weight $\geq 120 \mathrm{~kg}$ or $\mathrm{BMI}>40 \mathrm{~kg} / \mathrm{m}^{2}$ were consistent with the main results of the AMPLIFY trial. Across different body weight or BMI categories, compared with enoxaparin/warfarin, apixaban had similar rates of recurrent VTE or VTE-related death and lower rates of major bleeding (significant for body weight $>60$ to $<100 \mathrm{~kg}$ and $\mathrm{BMI}>35$ to $40 \mathrm{~kg} / \mathrm{m}^{2}$ groups) and the composite of major or CRNM bleeding (significant for all groups). There were no clinically meaningful differences in apixaban exposure between patients in the high and low body weight groups. Taken together, the findings of this post hoc analysis support the use of apixaban in patients with body weight $\geq 120 \mathrm{~kg}$ or BMI $>40 \mathrm{~kg} / \mathrm{m}^{2}$.

Prospective studies evaluating the efficacy and safety of apixaban for the treatment of VTE in obese patients with body weight $\geq 120 \mathrm{~kg}$ or BMI $>40 \mathrm{~kg} / \mathrm{m}^{2}$ are needed to confirm these findings and inform clinical decisions.

\section{ACKNOWLEDGMENTS}

The authors would like to thank all study participants for their involvement in the study.

Funding. Bristol Myers Squibb and Pfizer sponsored the AMPLIFY trial and the analysis reported here. The sponsors collected and maintained the data, and the academic authors had access to the data at all times through the sponsors. The sponsors supported the journal's rapid service fee.

Medical Writing and Editorial Assistance. Professional medical writing and editorial assistance were provided by Raya Mahbuba at Caudex and were funded by Bristol Myers Squibb and Pfizer.

Authorship. All named authors meet the International Committee of Medical Journal Editors (ICMJE) criteria for authorship for this article, take responsibility for the integrity of the work as a whole, and have given their approval for this version to be published.

Prior Publication. The analysis of the results by body weight group were presented at the 61st American Society of Hematology (ASH) Annual Meeting and Exposition; December 7-10, 2019; Orlando, FL, USA.

Disclosures. Alexander Cohen has received research support from Bayer, Boehringer Ingelheim, Bristol Myers Squibb, Daiichi Sankyo, GlaxoSmithKline, Merck Serono, Johnson and Johnson, Mitsubishi Pharma, Pfizer, Sanofi, and Schering Plough. Additionally, Alexander Cohen has received consultant fees and/or honoraria from Astellas, Bayer, Boehringer Ingelheim, Bristol Myers Squibb, Daiichi Sankyo, GlaxoSmithKline, Johnson and Johnson, Merck Serono, Mitsubishi Pharma, Pfizer, Portola Pharmaceuticals, Sanofi, Schering Plough, Takeda, and XO1. Sharon Pan is an employee of Pfizer. Wonkyung Byon, Bushra S. Ilyas, and Theodore C. Lee are employees and hold stock options and/or bond holdings in Pfizer. Thomas Taylor has nothing to disclose.

Compliance with Ethics Guidelines. The protocol was approved by the institutional review board of each participating study center (full list of institutional review boards that approved the study is included as supplementary material). All patients provided written informed consent. This study was conducted in accordance with the Declaration of Helsinki.

Data Availability. All data generated or analyzed during this study are included in this published article as supplementary information files. The datasets generated during and/or analyzed during the current study are available 
from the corresponding author on reasonable request.

Open Access. This article is licensed under a Creative Commons Attribution-NonCommercial 4.0 International License, which permits any non-commercial use, sharing, adaptation, distribution and reproduction in any medium or format, as long as you give appropriate credit to the original author(s) and the source, provide a link to the Creative Commons licence, and indicate if changes were made. The images or other third party material in this article are included in the article's Creative Commons licence, unless indicated otherwise in a credit line to the material. If material is not included in the article's Creative Commons licence and your intended use is not permitted by statutory regulation or exceeds the permitted use, you will need to obtain permission directly from the copyright holder. To view a copy of this licence, visit http:// creativecommons.org/licenses/by-nc/4.0/.

\section{REFERENCES}

1. World Health Organization. WHO obesity and overweight fact sheet. 2020. https://www.who.int/ news-room/fact-sheets/detail/obesity-andoverweight. Accessed 31 August 2020.

2. Blokhin IO, Lentz SR. Mechanisms of thrombosis in obesity. Curr Opin Hematol. 2013;20:437-44.

3. Vilahur G, Ben-Aicha S, Badimon L. New insights into the role of adipose tissue in thrombosis. Cardiovasc Res. 2017;113:1046-54.

4. Hotoleanu C. Association between obesity and venous thromboembolism. Med Pharm Rep. 2020;93:162-8.

5. Abdollahi M, Cushman M, Rosendaal FR. Obesity: risk of venous thrombosis and the interaction with coagulation factor levels and oral contraceptive use. Thromb Haemost. 2003;89:493-8.

6. Stein PD, Beemath A, Olson RE. Obesity as a risk factor in venous thromboembolism. Am J Med. $2005 ; 118: 978-80$.

7. Martin K, Beyer-Westendorf J, Davidson BL, Huisman MV, Sandset PM, Moll S. Use of the direct oral anticoagulants in obese patients: guidance from the SSC of the ISTH. J Thromb Haemost. 2016;14: 1308-13.

8. Bristol Myers Squibb. Eliquis ${ }^{\circledR}$ (apixaban tablets). Prescribing information. November 2019. https:// packageinserts.bms.com/pi/pi_eliquis.pdf. Accessed 26 December 2019.

9. Byon W, Sweeney K, Frost C, Boyd R. Population pharmacokinetics, pharmacodynamics, and exploratory exposure-response analyses of apixaban in subjects treated for venous thromboembolism. CPT Pharmacom Syst Pharmacol. 2017;6:340-9.

10. Upreti VV, Wang J, Barrett YC, et al. Effect of extremes of body weight on the pharmacokinetics, pharmacodynamics, safety and tolerability of apixaban in healthy subjects. Br J Clin Pharmacol. 2013;76:908-16.

11. Agnelli G, Buller HR, Cohen A, et al. Oral apixaban for the treatment of acute venous thromboembolism. N Engl J Med. 2013;369:799-808.

12. Frost CE, Byon W, Song Y, et al. Effect of ketoconazole and diltiazem on the pharmacokinetics of apixaban, an oral direct factor Xa inhibitor. $\mathrm{Br} \mathrm{J}$ Clin Pharmacol. 2015;79:838-46.

13. Chang M, Yu Z, Shenker A, et al. Effect of renal impairment on the pharmacokinetics, pharmacodynamics, and safety of apixaban. J Clin Pharmacol. 2016;56:637-45.

14. Frost CE, Song Y, Shenker A, et al. Effects of age and sex on the single-dose pharmacokinetics and pharmacodynamics of apixaban. Clin Pharmacokinet. 2015;54:651-62.

15. Martin AC, Thomas W, Mahir Z, et al. Direct oral anticoagulant concentrations in obese and high body weight patients: a cohort study. Thromb Haemost. 2021;121:224-33.

16. Covert K, Branam DL. Direct-acting oral anticoagulant use at extremes of body weight: literature review and recommendations. Am J Health Syst Pharm. 2020;77:865-76.

17. Sebaaly J, Kelley D. Direct oral anticoagulants in obesity: an updated literature review. Ann Pharmacother. 2020;54:1144-58.

18. Di Nisio M, Vedovati MC, Riera-Mestre A, et al. Treatment of venous thromboembolism with rivaroxaban in relation to body weight. A subanalysis of the EINSTEIN DVT/PE studies. Thromb Haemost. 2016;116:739-46.

19. Elshafei MN, Mohamed MFH, El-Bardissy A, et al. Comparative effectiveness and safety of direct oral 
anticoagulants compared to warfarin in morbidly obese patients with acute venous thromboembolism: systematic review and a meta-analysis. J Thromb Thrombolysis. 2021;51:388-96.

20. Coons JC, Albert L, Bejjani A, Iasella CJ. Effectiveness and safety of direct oral anticoagulants versus warfarin in obese patients with acute venous thromboembolism. Pharmacotherapy. 2020;40: 204-10.

21. Kushnir M, Choi Y, Eisenberg R, et al. Efficacy and safety of direct oral factor Xa inhibitors compared with warfarin in patients with morbid obesity: a single-centre, retrospective analysis of chart data. Lancet Haematol. 2019;6:e359-65.

22. Wysokinski WE, Froehling DA, Houghton DE, et al. Effectiveness and safety of apixaban and rivaroxaban for acute venous thromboembolism therapy in patients with extremes in bodyweight. Eur J Haematol. 2020;105:484-94.

23. Spyropoulos AC, Lipardi C, Xu J, et al. Improved benefit risk profile of rivaroxaban in a subpopulation of the MAGELLAN study. Clin Appl Thromb Hemost. 2019;25:1076029619886022. 